\title{
Innovative transport technologies as a basis of cities' and regions' progressive development
}

\author{
Tatiana Filanova ${ }^{1, *}$, and Ekaterina Mikhaylova ${ }^{1}$ \\ ${ }^{1}$ Samara State Technical University, Institute of Architecture and Civil Engineering, 194, \\ Molodogvardeyskaya St, 194, 443001, Samara, Russia
}

\begin{abstract}
The article raises modern Russian cities' vital problems which are associated with the traffic situation - problems of ecology, safety, economy, lack of mobility. The author reviews the possibility of solving these problems by means of introducing wire transport into modern life. The aim of the research is to investigate the factor influence of new transport technologies on the future of cities, regions and their population. The article deals with the aspects of possible influence of wire transport SkyWay on the functioning of cities and regions, it provides a comparison with the existing urban and intercity kinds of transport, future changes are forecast. Using the example of the city of Samara, the author shows all aspects of the positive effects of transport innovations on the life of the city and its citizens, as a complement to the existing transport systems.
\end{abstract}

\section{Introduction}

Today in the life of modern cities and agglomerations there is a period when the speed of transportation is significantly behind the global development of information technologies, and the existing transport systems are in "conflict" with the life of cities and citizens. The majority of current urban planning and social problems is connected with the traffic situation in cities and regions.

\subsection{The main problems of modern cities connected with traffic}

Since the 1990s, rapid growth of vehicles to population ratio has been taking place in Russia. Similar growth was recorded in Western countries in the 30-50-ies of the twentieth century (Figure 1). This steady process, along with positive changes, has also brought a lot of negative phenomena into the life of Russian cities - the cities are "paralyzed" with systematic road jams, as a result the speed and reliability of transportation has sharply reduced, the number of accidents and the amount of harmful atmospheric emissions has increased. [1]

The increase in the number of vehicles on the roads leads to the need to expand roads and to reconstruct the existing road network, but, in practice, these measures only "palliate"

\footnotetext{
${ }^{*}$ Corresponding author: filanovatv@mail.ru
} 
the situation, moreover the living space of the citizens is significantly reduced - areas, that could have been green zones or pedestrian spaces, are covered with asphalt.

A

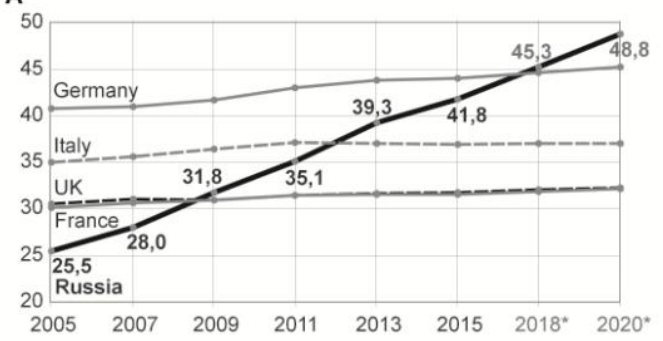

c
B

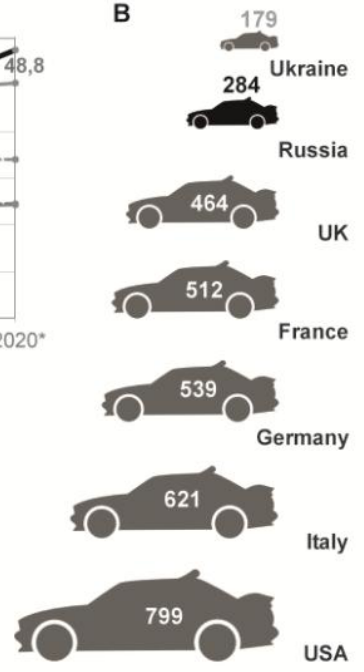

Fig. 1. The vehicles to population ratio in Russia [3]: A - the dynamics of growth of the number of vehicles in Russia, as compared to European countries, in 2005-2015, the forecast for 2018 - 2020 , mln vehicles; B - The number of vehicles per one thousand people in 2015; C - The growth of vehicles to population ratio in Russia during the years 1970-2015, the forecast for 2020 (* - forecast parameters)

There is a growing negative impact on the environment - exhaust fumes containing lead and other heavy metals are emited into the atmosphere and drift over the ground, which is especially harmful for the health of children. [2]

Security problems are becoming more and more vital - every day citizens put their lives at risk when they travel by car, or even cross the street. According to statistics, cars are the most dangerous kind of transport: every year 1,2 million people in the world are killed in road traffic accidents, and 9 million become disabled. In Russia 72800 accidents took place during the first half of 2016, in which 8.1 thousand people were killed $[3,4]$. We may assume that these numbers will be growing, because only in Samara up to 10 thousand new cars are added every year (Figures 1,3 ).

Economic problems are becoming more and more vital too, because any modern transport is costly, both its construction and operation. None of the existing kinds of transport, ground or underground, pay back, and they require annual state subsidies.

Cities are growing, free territories that are far from the city center are built up, the flow of vehicles in the direction of the center is increasing. Social problems associated with lack of mobility are becoming more and more vital - the average speed of traffic in the city, taking into account traffic jams and stops, does not exceed $25-30 \mathrm{~km} / \mathrm{h}$.

\subsection{Finding solutions}

If no measures are taken, by 2020 a traffic collapse will take place in many cities. Realizing this, the city authorities are looking for solutions, these problems are discussed by the media and experts in the sphere of transport.

The main objective was to create the conditions for easy and comfortable living of citizens in towns, i.e. to find cost-effective, socially healthy and environmentally 
sustainable technologies $[1,5,6]$. Russian President Vladimir Putin stressed more than once the need for innovation in all spheres of life. To date, all proposals and changes in the sphere of transport are just about higher comfort level (bigger windows, a warm comfortable lounge, Wi-Fi), which is not an innovation and does not affect speed and travel time. Innovations in transport must focus primarily on safety, environment friendliness and cost effectiveness, along with maximum possible travel speed [7].

Today SkyWay - an innovative transport technology - is entering the transport market. It is a kind of rail transport, developed by the Russian engineer and innovator A.E. Unitsky. This transport system is called the "transport of the future", it is seen as an addition to the existing infrastructure of public passenger transport, and it may be a real solution to the above-described problems.

The aim of the research is to investigate the factor influence of new transport technologies on the future of cities, regions and their population.

\section{Materials and Methods}

Research methodology supposes following methods: statistic analysis method, comparative and matching method, sociological survey method, analysis and synthesis method, forecasting method. Research territorial boundaries are cities and regions of the Russian Federation. For effective solution of traffic problems the results of sociological survey of automobilists in Samara city in 2010 are used. On the forecast basis a design proposal of targeted use of wire technologies in Samara city is drafted.

\subsection{Sky Way wire transport. Main kinds and technical characteristics of wire transport}

Sky Way is a unique system, which has got no analogues in the world: these are carriage modules on steel wheels moving along rails above the ground on the second level. The construction of the rails includes pre-tensioned wires, that provide the perfect straightness of the track structure, which is mounted on poles without massive concrete overpasses. The system provides high-speed transportation of passengers and goods both in cities and between cities, regions, countries and even continents.

The characteristic features of this kind of transport are as follows: the speed is from $120-150 \mathrm{~km} / \mathrm{h}$ (in the city) to $500 \mathrm{~km} / \mathrm{h}$ (high-speed intercity); the capacity of the stock is from 2-50 people (in the city) to 500 people (in the city), plus 100 tons of goods. The gradient of the way is up to $10 \%$, with special calculation it's up to $30 \%$. The volume of high-speed intercity traffic is: passengers - up to 1 million people / a day, goods - 100 tons / a day. The cost of the high-speed line, including the cost of the stock, passenger stations and infrastructure, is over 3 million USD / $\mathrm{km}$. The net cost of high-speed transport is 5 times less than the net cost of travelling by high-speed railway, by magnetic cushion train or by plane. The return on construction costs is 2-4 years.

Compared to the existing transport systems, SkyWay has got significant competitive advantages. (see Table 1, Fig.2) [8-10]

Table 1. The main parameters of Sky Way compared to other kinds of city transport

\begin{tabular}{|c|c|c|c|c|c|}
\hline Kind of transport & $\begin{array}{c}\text { Wire } \\
\text { transport } \\
\text { Sky Way }\end{array}$ & Metro & $\begin{array}{c}\text { Light } \\
\text { rail }\end{array}$ & Tram & Car \\
\hline Environmental factor & $\mathbf{1 , 0}$ & 0,5 & 0,7 & 0,6 & 0,2 \\
\hline Safety factor & $\mathbf{1 , 0}$ & 0,8 & 0,7 & 0,6 & 0,3 \\
\hline
\end{tabular}




\begin{tabular}{|c|c|c|c|c|c|}
\hline Kind of transport & $\begin{array}{c}\text { Wire } \\
\text { transport } \\
\text { Sky Way }\end{array}$ & Metro & $\begin{array}{c}\text { Light } \\
\text { rail }\end{array}$ & Tram & Car \\
\hline $\begin{array}{c}\text { Parameter } \\
\text { Speed rate / including stops, km per } \\
\text { hour }\end{array}$ & $\mathbf{1 5 0} / \mathbf{1 0 0}$ & $70 / 50$ & $80 / 55$ & $40 / 25$ & $60 / 30$ \\
\hline $\begin{array}{c}\text { Cost of constructing one kilometer of } \\
\text { the line, mln USD }\end{array}$ & $\mathbf{3 - 6}$ & $120-140$ & $60-80$ & $15-20$ & $60-80$ \\
\hline Return on construction costs, yrs & $\mathbf{2 - 3}$ & 5 & 2,5 & 2,5 & 20 \\
\hline
\end{tabular}

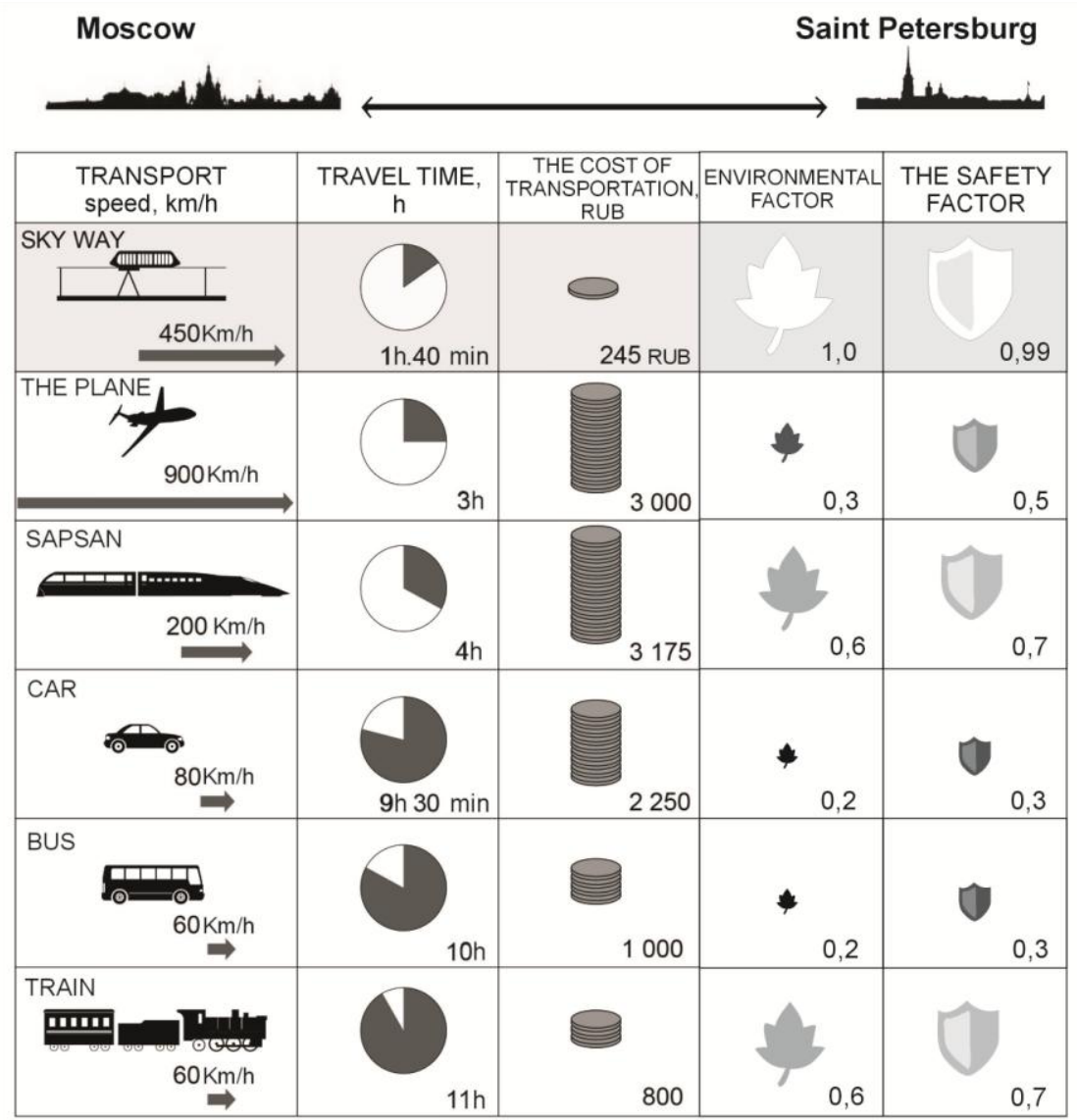

Fig. 2. Benchmarking analysis of intercity Sky Way and other kinds of high speed transport, using the example of the route Moscow - St Petersburg

\subsection{Performance capabilities of wire transport system in cities (the case of Samara)}

The practical implementation is taking place in Belarus, and the concepts of city public, high-speed and freight wire transport have already been tested. Over 80 cities and regions of the world are getting ready to use this transport system, including not only Russia, but also Australia, India, Columbia, Bolivia, Kazakhstan, Georgia, Ukraine, the Baltic 
countries. SkyWay targeted projects are developed in many regions of Russia Yekaterinburg, Chelyabinsk, St. Petersburg, Ulyanovsk, Nizhny Novgorod, Samara, Togliatti.

A recent poll in the city of Togliatti has shown the citizens' interest in the introduction of the new kind of transport $-63.9 \%$ of the respondents have approved the ability to quickly move between the districts of Togliatti with the help of the new environment-friendly transport. [11]

Let us consider the effect of introducing SkyWay transport system in the city of Samara. This large city with a population of over 1.1 million people is the economic, scientific, educational and cultural center of the Samara Region, and its traffic is admitted to be one of the busiest in Russia. The existing city infrastructure can not cope with the traffic flow, and the urban development does not allow expanding the roads to the level required in a modern city. The number of cars is constantly growing, the problem of traffic jams and lack of parking spaces is becoming more and more vital every year (Figure 3 ). In the city center, due to the lack of parking spaces, cars stand on the carriageway of streets, and this aggravates the problems of transport accessibility.
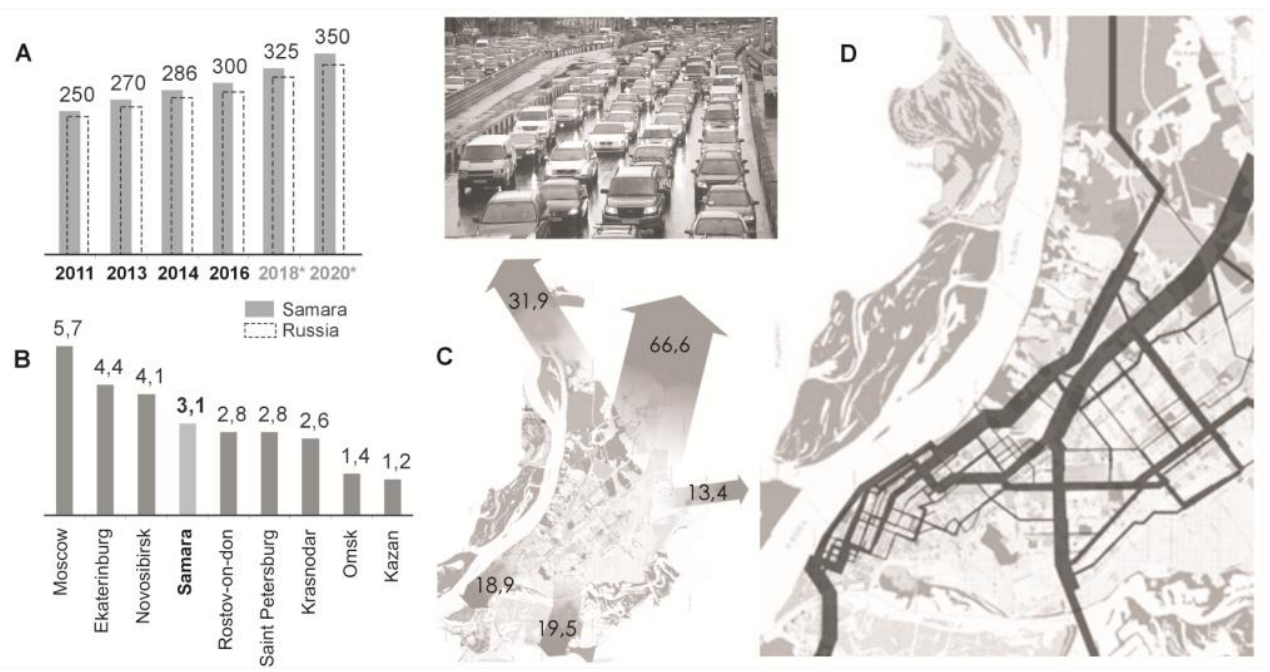

Fig. 3. Traffic situation in Samara: A - the growth of vehicles to population ratio in Samara during the period 2011-2016 [3], the forecast for 2018-2020 (* - forecast parameters); B - the average rate of traffic jams in different cities, as compared to Moscow scale [12]; $\mathrm{C}$ - the ranking of load on the main exits from the city, as per the results of a poll of car drivers in Samara in 2010 (\% of respondents) [11]; D - the busiest streets of Samara, as per the results of a poll of car drivers in Samara in 2010 [11].

A project of SkyWay trace routes around the city with passages across the rivers Volga and Samara (see Figure 4) is under development. This project includes a straight route along Karl Marx avenue, the aim being to lessen the burden on the main longitudinal thoroughfares - Moskovskoe Highway and Novo-Sadovaya Street - which are currently experiencing especially heavy traffic load. Also it's planned to organize a SkyWay tourist route (light passenger line) along the embankment of the Volga.

As estimated, the implementation of the project will significantly improve the traffic situation in the city: lessen the burden on the existing thoroughfares, optimize the transportation of passengers and goods, in the long term - eliminate traffic jams on city roads. The residents of remote new buildings will be able to move fast and freely in the direction of the city center for work or other purposes. Besides, there will appear non-stop 
transport links with the districts, which are separated from the city by water barriers currently the residents of such districts have difficulty communicating with the main part of the city.

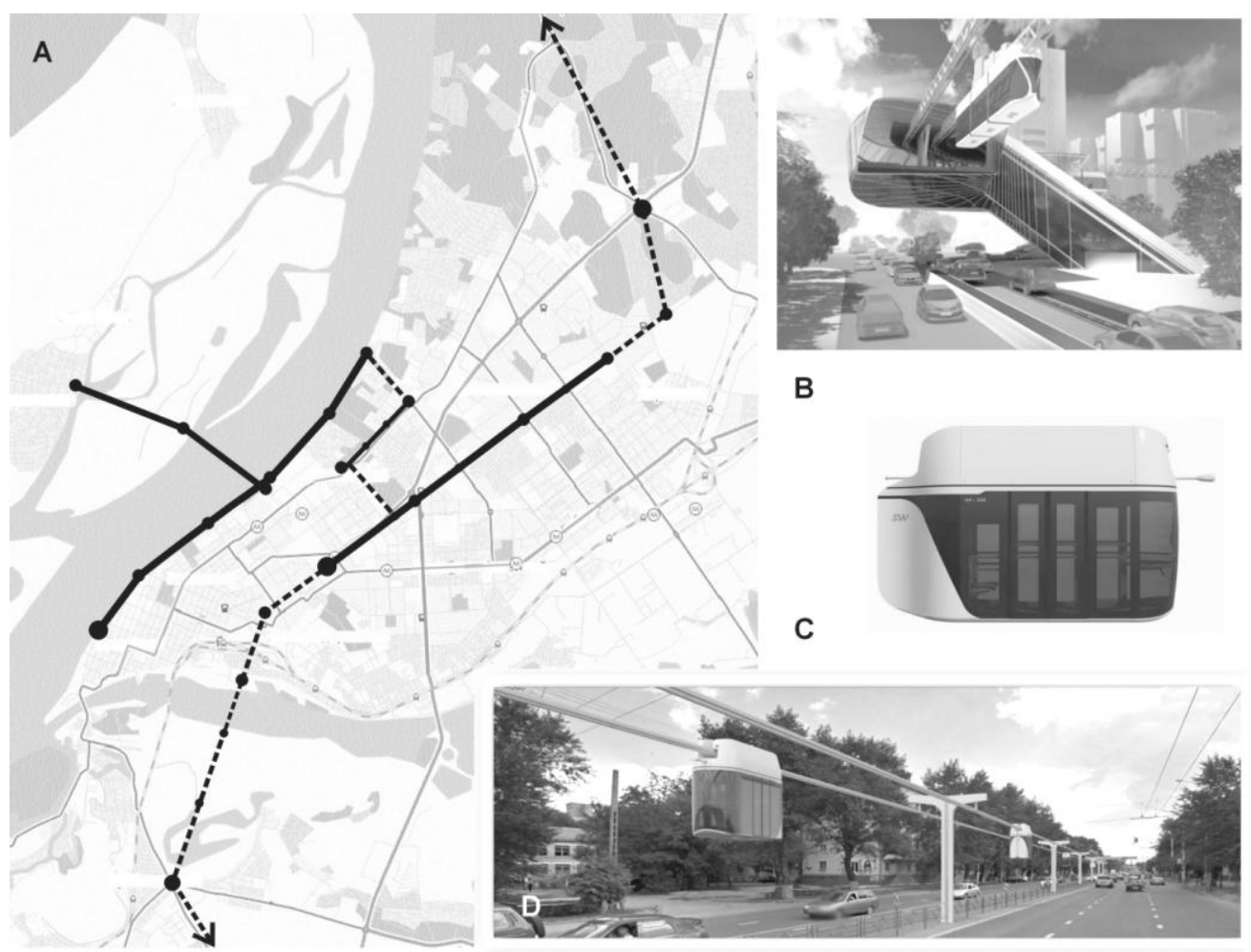

Fig. 4. Design proposals for the use of wire transport in the city of Samara: A - pre-design proposal for the 1st stage of SkyWay trace in Samara; B - SkyWay turn-round station, built at the crossing of city thoroughfares; C - SkyWay cable module passenger carriage, designed for 14 passengers; D SkyWay line, arranged on the separating strip of the existing city thoroughfare.

\section{Results}

\subsection{Research of the effect of Sky Way system on different aspects of life in cities and regions}

The innovativeness of SkyWay transport consists in the possibility of combining a significant increase in speed with safety, environment friendliness, comfort, low cost of transportation.

\subsubsection{Environment friendliness}

The introduction of wire transport will allow not only preserving, but also for the first time in the history of transport - improving the environmental situation in cities. Above all, this will be due to low resource intensity and energy consumption at all the stages of life cycle (design, construction, operation and disassembly) and due to the high efficiency of technical solutions. The road which is arranged on the upper level does not hinder the flow 
of groundwater and surface water, or the movement of people and animals, or the work of machnies. This is because when the track structure is arranged only a small area of the earth's surface is occupied (only the area under the track structure supports). The use of electric traction will completely eliminate harmful emissions.

\subsubsection{Reliability and safety}

Wire transport means improving the reliability and safety by all-weather and year-round operation of the transport system under any natural and climatic conditions. Sky Way is resistant to icing and glaciation, snow drifts, fogs, dust and sand storms. It is resistant to natural disasters: earthquakes with magnitude up to 10 on the Richter scale; floods, overflows of rivers with water depth up to 10 meters and more; hurricanes with speed up to $250 \mathrm{~km} / \mathrm{h}$ and more; tsunamis - with wave height 20 meters and more; it is resistant to terrorist attacks.

\subsubsection{Solution of economic problems}

Reduction of capital costs for construction and operation takes place due to the significant reduction of the area occupied by the line and by the infrastructure; due to the elimination of earthfills, caves, tunnels, bridges and overpasses; due to the reduction of metal consumption when arranging the track structure; due to the reduction of energy consumption; due to obviating the need to clean the track structure from ice and snow in winter. For these reasons the fare will be low too, as calculated - not more expensive than the cost of travel by city public transport, at the same time the system has got high capacity, and it will pay off in 2-4 years.

\section{Discussion}

New transport technologies, aimed primarily at increasing the speed of movement, will allow changing the entire infrastructure of cities and the lifestyle of the population, and at the same time will improve safety, environment friendliness and comfort. The implementation of wire transport system will generally contribute to the economic revival of the city and of the whole country, will improve the traffic situation - help to lessen the burden on the roads, to make remote areas accessible and to make long trips faster. The large speed of innovative transport will allow people to work in metropolitan areas and to live in green suburbs, and it will take them 15-30 minutes to travel to work, comfortably and without traffic jams.

The introduction of SkyWay will change the architectural appearance of cities, there will be new horizons of activity for architects and urbanists, related to the design of routes, industrial sites, objects for wire transport infrastructure, stations and interchanges, that will link SkyWay with other kinds of transport [10,11].

\section{Conclusions}

Thus, the introduction of SkyWay into the life of modern cities and regions will efficiently complement the existing communications and will help to solve many vital problems. Perfect transport technologies are the basis of technological and economic development of society, they offer the opportunity to quickly and safely travel, transport goods, build new cities and develop the existing ones, bring new land into cultivation, as well as form a new social culture of the citizens. 


\section{References}

1. V.R. Vuchic, Transport in livable cities. Territory of the future (2011)

2. L.G. Goverdovskaya, A.K. Yushantsev, Urban construction and architecture 1, 72-80 (2015). doi: 10.17673/Vestnik.2015.01.12

3. Autostat. Analytic agency: Official site. https://www.autostat.ru

4. Transport. Federal State Statistics Service: Official site. http://www.gks.ru/wps/wcm/connect/rosstat_main/rosstat/ru/statistics/enterprise/ transport/

5. E.S-Kh. Magomadova, A.Kh. Mamadiev, Proceedings of Platov South Russian State Polytechnic University (NPI) 5, 85-90 (2015)

6. A.E. Kondratiev, Theory and practice of social development, 4343 (2012)

7. I. Ilyina, URBAN magazine 3, 17-27 (2014)

8. A. E. Unitsky, Unitsky's transportation system (UTS) in questions and answers. 100 questions - 100 answers (2012)

9. SkyWay official site. http://www.rsw-systems.com/?r=rich

10. T.V. Filanova, Urban construction and architecture 4, 34-39 (2014). doi: 10.17673/Vestnik.2014.04.6

11. K.P. Matskievich, V.M. Melnikova, T.V. Filanova, P.Y. Koriakina, K.E. Nikonov, Togliatti: development prospects. Research work "Social studies" (2016)

12. Regional portal Cамара.py. http://samara.ru/read/57295

13. Transport in Russia: problems and prospects - 2015: Proceedings of anniversary international research and application conference V. 2 (2015). 